\title{
Best Imaginable Health
}

National Cancer Institute

\section{Source}

National Cancer Institute. Best Imaginable Health. NCI Thesaurus. Code C111680.

The best state of well-being an individual can conceive of experiencing. 